\title{
Políticas culturais e bibliotecas do Cariri cearense
}

\author{
Vitória Gomes Almeida \\ Mestranda; Universidade Federal da Paraíba, João Pessoa, PB, Brasil; \\ vitoriagomesalmeida@yahoo.com.br \\ Maria das Graças Targino \\ Doutora; Universidade Federal da Paraíba, João Pessoa, PB, Brasil; \\ gracatargino@hotmail.com
}

\begin{abstract}
Resumo: Este artigo discute a cultura e sua instrumentalização sob a forma de políticas públicas no âmbito das bibliotecas brasileiras. Objetiva saber em que medida as bibliotecas estão inseridas nas políticas nacionais de cultura - Plano Nacional de Cultura e o Plano Nacional do Livro e Leitura - e como vêm sendo aplicadas as metas desses planos. Estabelece um recorte de análise nos programas e projetos desenvolvidos em três bibliotecas do Cariri cearense Biblioteca Inspiração Nordestina, Juazeiro do Norte; Biblioteca do Centro de Artes e Esportes, Barbalha; e Biblioteca Pública do Crato, Crato, em razão da pluralidade e diversidade cultural existente nessa localidade. Realiza o estudo por meio de revisão bibliográfica e da aplicação de questionários para bibliotecários e auxiliares das bibliotecas analisadas. Conclui-se que apesar de existirem muitas dificuldades e barreiras para o pleno funcionamento das bibliotecas, as ações e atividades contribuem para a efetivação das metas propostas nos planos, bem como constata a relevância dessa discussão dentro da Biblioteconomia, uma vez que falar em política cultural é referir-se aos fenômenos informacionais, que evocam questões de uso, apropriação e circulação da informação, assim como à produção e organização do conhecimento.
\end{abstract}

Palavras-chave: Políticas públicas de cultura. Bibliotecas. Ações culturais. Cariri cearense.

\section{Introdução}

A cultura, na condição de objeto de estudo, perpassa diferentes áreas do conhecimento adquirindo diferentes conceituações e entendimentos. Tal multiplicidade de significações constata a complexidade e a importância do termo em questão, reconhecido institucionalmente como mecanismo capaz de 
atuar em esferas econômicas, políticas, sociais e educacionais, de tal forma que a cultura vem sendo instrumentalizada na contemporaneidade sob a forma de políticas públicas. Estas figuram, consensualmente e como Hochman, Arretche e Marques (2007) reafirmam, como conjunto de programas, ações e atividades a cargo do Estado, contando com a participação de entes públicos e privados, que visam assegurar aos indivíduos o direito de cidadania, tanto de forma genérica quanto para determinados segmentos sociais, culturais, econômicos ou étnicos.

No Brasil, as políticas culturais possuem ações pioneiras se comparadas empiricamente com os demais países da América Latina e assumem, a partir da Constituição de 1988, maior destaque político. Hoje, sua gestão é realizada em âmbito estatal pelo Ministério da Cultura (Minc), que dentre as diversas atividades de fomento e promoção da cultura em suas mais variadas expressões e linguagens, encontra-se direcionada para o cumprimento das metas propostas no Plano Nacional de Cultura (PNC). Outra política nacional de grande abrangência é o Plano Nacional do Livro e Leitura (PNLL), instituído em 10 de agosto de 2006, pelo MinC, na gestão de Gilberto Gil. Aliás, nível maior de detalhamento acerca dos dois Planos está em suas páginas eletrônicas oficiais, respectivamente, http://www.cultura.gov.br/plano-nacional-de-cultura-pnc $\underline{\mathrm{e}}$ http://www.cultura. gov.br/pnll.

O destaque em torno das políticas culturais e do conhecimento de várias metas relacionadas às bibliotecas desperta o interesse em compreender de que maneira tais metas estão sendo efetivamente aplicadas nas bibliotecas da região do Cariri cearense. Isto é, justifica-se a escolha do tema, em razão do conhecimento de que é comum a referência entre pesquisadores, gestores culturais e artistas da região falar desse lugar como caldeirão cultural. Expresso em várias linguagens e gerido por grupos independentes, bem como por instituições públicas e privadas (Serviço Social do Comércio, Centro Cultural do Banco do Nordeste, secretarias de cultura municipais, Pró-Reitoria de Cultura da Universidade Federal do Cariri...), o cenário cultural da região é movimentado graças a ações e políticas desenvolvidas por essas instituições.

No contexto das bibliotecas, inquieta saber até que ponto são elas partes integrantes de políticas nacionais, especificamente do PNC e do PNLL, ou se 
são apenas ações culturais pontuais. Para alcançar tal objetivo, analisam-se as metas das políticas públicas de cultura voltadas para três bibliotecas da região Biblioteca Inspiração Nordestina, Juazeiro do Norte; Biblioteca do Centro de Artes e Esportes, Barbalha; e Biblioteca Pública do Crato, Crato. Em termos metodológicos, além de revisão bibliográfica acerca da temática, aplica-se a técnica de questionário aberto a bibliotecários e/ou auxiliares à frente da gestão das referidas bibliotecas para que respondam acerca das atividades e iniciativas realizadas na biblioteca onde atuam - identificação das ações (se existentes); público-alvo; vinculação ao MinC/recebimento de recursos do Ministério (se for o caso); aspectos positivos e negativos das referidas atuações.

Informações obtidas e reflexões sobre a temática estão estruturadas em seções. De início, levantamento historiográfico não exaustivo das políticas culturais brasileiras e eventuais resultados de sua implantação. Seguem, então, apresentação e discussão das ações das bibliotecas do Cariri cearense.

\section{Políticas culturais no Brasil: contexto histórico e reflexões}

O despertar de consciência relativa à cultura, memória, identidade, patrimônio e participação da sociedade como meio para o desenvolvimento endógeno dos países, levando à criação de planos, políticas e documentos internacionais com essa dimensão, é bastante recente e provém da atuação da Organização das Nações Unidas para a Educação, Ciência e Cultura (UNESCO).

Percebe-se que as estratégias de desenvolvimento econômico internacional, aplicadas numa perspectiva unicamente de crescimento econômico, constituem um modelo falido, uma vez que tendem a acentuar desigualdades sociais ao invés de minimizá-las rumo ao desenvolvimento. Por essa razão, adotam-se gradativamente a cultura, o patrimônio e a identidade nas iniciativas das políticas públicas como fontes essenciais para o crescimento e o progresso dos Estados-nações (MEDEIROS, 2004).

No Brasil, não é possível assegurar a existência de políticas culturais no período da Colônia assim como na Primeira República. Efetivam-se apenas na Era Vargas, 1930 a 1945 (RUBIM, 2007), por meio de políticas culturais 
voltadas para consolidar o Brasil como Estado nacional e implementadas, sobretudo, visando à legitimação do autoritário regime do Estado Novo.

Na década de 30, destaca-se a criação do Serviço do Patrimônio Histórico Artístico Nacional (SPHAN), com a finalidade de gerir e executar ações referentes ao patrimônio cultural do Brasil. Apesar de se identificarem como medidas de preservação voltadas unicamente para bens materiais, configuram-se como importante iniciativa por ser o SPHAN a primeira instituição criada no país para a proteção do patrimônio cultural, além de ser a entidade oficial mais antiga de proteção de bens culturais na América Latina.

Uma crítica recorrente é que, no anteprojeto do SPHAN, criado por Mário de Andrade, a atenção com a cultura imaterial se fazia presente, porém não se efetivava devido aos interesses políticos da época de desenvolver uma "alta cultura" no país. Manifestações e expressões populares como as oriundas do folclore, além de consideradas parte de uma "cultura menor", viviam numa rígida política de vigilância e controle "[...] a qual foi imposta a obrigatoriedade do uso de temáticas cívicas e apologéticas da ordem e do trabalho (o novo fundamento da cidadania)." (MENDONÇA, 1990, p. 346). Na prática, a nova política é atribuída, à época, a meios, como o rádio ou a ritmos, como o samba.

No que se refere às bibliotecas, salienta-se a criação do Instituto Nacional do Livro (INL), também no ano de 1937, cujos objetivos priorizam a edição de obras literárias e a elaboração de uma enciclopédia e de um dicionário nacional, além da expansão por todo o território brasileiro de bibliotecas públicas.

Aliás, se a democratização da informação deve ser exercida, continuamente e ininterruptamente em qualquer biblioteca ou centro de documentação, é na biblioteca pública que assume maior dimensão, como instrumento de estímulo à construção da cidadania. Em sua esfera, devem estar à disposição dos cidadãos, qualquer que seja sua escolaridade, informações que lhes propiciem ir à luta, em busca de seus direitos e da compreensão de seus deveres, para contribuição efetiva ao progresso da comunidade.

Isto é, no âmago de uma biblioteconomia moderna voltada para o social e da pretendida popularização da biblioteca, independentemente da terminologia 
utilizada (biblioteca popular, biblioteca ação cultural, biblioteca verdadeiramente pública e outras denominações), a biblioteca pública é uma:

[...] instituição essencialmente social, a que compete a preservação e disseminação dos valores que integram a cultura de um país e/ou de um povo. Para tanto, em qualquer circunstância, deve maximizar a utilidade social dos registros gráficos, mantendo vivas a identidade e a memória da cultura local (TARGINO, 2006, p. 63).

Como aspecto positivo para as bibliotecas públicas, evidencia-se o fato de terem sido implantadas em grande número no país e nos diversos Estados brasileiros. Em contrapartida, essas medidas reforçam o projeto ideológico estado novista, o qual objetiva a formação cultural da população por meio da valorização de

[...] um corpus de ideias, crenças e valores centrados na unidade de um único Brasil, num processo de uniformização, no qual o sentimento de identidade nacional permitisse a omissão da divisão social, a direção das massas pelas elites e a valorização da "democracia racial", que teria homogeneizado num povo branco a população brasileira [...] O índio, objeto dos livros didáticos, era ainda o nativo encontrado pelos portugueses no século XVI, não o índio degradado pela conquista europeia, que persistia em sobreviver, nos séculos posteriores (ABUD, 1998, p. 3).

Nas décadas seguintes, 1940 e 1950, ocorre a criação da Comissão Nacional de Folclore (CNFL), considerada como ponto de partida para o estudo do folclore e das manifestações culturais do país, e que resulta em 1958, numa Campanha de Defesa do Folclore Brasileiro (CDFB), ligada ao então Ministério da Educação e Cultura. Desse período até 1964, se dá, na iniciativa privada, o avanço da área cultural, sem grandes intervenções do Estado, que mantém a estrutura vigente, porém, com ações pontuais de repasse de recursos para algumas instituições culturais, mas nada que possa ser chamado de política cultural de financiamento (CALABRE, 2007).

Em 1961, é a vez do Serviço Nacional de Bibliotecas (SNB), cujo foco está voltado para a organização e o controle bibliográfico, através da criação, organização e estruturação de bibliotecas públicas. Entretanto, segundo Caldas e Tálamo (2007, p. 3), “[...] vale ressaltar que o interesse com os aspectos de incentivo à leitura ainda se encontrava distante das decisões governamentais. No 
Brasil, a inconstância das leis e decretos é notável [...]”, o que justifica a curta duração dessa medida, sete anos antes de o SNB ser submetido a grandes mudanças em sua política interna e estrutura, pós-golpe 1964.

Com o período da ditadura militar, seguem-se anos de repressão política e ideológica, assim como se percebe a existência de um mercado, como coloca Ortiz (2006), que incorpora tanto empresas privadas quanto instituições governamentais, no qual se verifica expressiva expansão no que tange à produção, à distribuição e ao consumo dos bens culturais.

A cultura passa a ser uma área privilegiada em relação a períodos anteriores do país, uma vez que o governo institui importantes órgãos estatais que administram e organizam a cultura. Dentre eles: em 1966, o Conselho Federal de Cultura (CFC) e o Instituto Nacional do Cinema; em 1969, a Empresa Brasileira de Filmes S.A. (Embrafilme); em 1975, o Centro Nacional de Referência Cultural (CNRC); e como política, é lançado no mesmo ano, o Plano Nacional de Cultura (primeiro plano de ação governamental com bases norteadoras de uma política cultural); em 1979, a Fundação Nacional PróMemória, entre outros.

O esforço de se construir uma política cultural em escala nacional (Embrafilme, Funarte [Fundação Nacional de Artes], Conselho Federal de Cultura, Fundação Pró-Memória) funda-se na reinterpretação das ideias de sincretismo e mestiçagem, procurando acomodá-las à perspectiva autoritária do Estado. Era preciso modelar uma imagem convincente de um Brasil autóctone, sem influências estrangeiras (o comunismo), harmônico e cordial (ORTIZ, 2013, p. 613).

É nesse contexto que o INL surge com novas atribuições se comparado com sua primeira fase de atuação, voltado, agora, para a estruturação no sistema empresarial dos livros, através da publicação (com ênfase nos didáticos) dos que são aprovados pela censura, proporcionando estímulo ao trabalho de editores e bibliotecas, contudo, sem desenvolver de fato uma política pública para elas (LEITÃO, 2010). Prioriza-se nessas instituições, por exemplo, o quantitativo ao invés de ações de mediação voltadas para as necessidades dos usuários ou do desenvolvimento de seus hábitos de leitura. 
Na segunda fase do período da ditadura militar, as bibliotecas continuam ligadas ao INL por meio da incorporação do SNB, marcado por uma política descontinuada, passando por três diferentes gestões. Desse período, destacamse: preocupação com uma política editorial de publicação, regida pela iniciativa privada e guiada pelos critérios da censura; descentralização no modelo de bibliotecas públicas, que propõe a implantação de bibliotecas volantes e de unidades culturais; modificação do papel da biblioteca pública que passa a ter função educativa em lugar da função cultural, com acervos voltados para a pesquisa escolar (na prática, meras transcrições); e a criação do Sistema Nacional de Bibliotecas Públicas (MEDEIROS; ALMEIDA; VAS, 2014).

Com o fim da ditadura, cria-se, em 1985, o MinC no governo de José Sarney, o que não corresponde à possibilidade de estabelecimento de uma nova política cultural no país.

Nova fase mais democrática inicia apenas com a promulgação da Constituição de 1988, na qual fica previsto o direito à cultura e às suas fontes, através da promoção e do financiamento de atividades culturais, garantindo a diversidade cultural do país. Calabre (2015) destaca dois tipos de gestão pública que afloram nos anos 80 - gerencial e societal. E diz:

\begin{abstract}
As propostas assentadas no modelo gerencial foram implementadas ao longo do governo do Presidente Fernando Henrique Cardoso (1994-2002), alinhadas a uma política neoliberal que predominava no cenário internacional. A proposta central de tal modelo era a da redução do tamanho e das funções do Estado até alcançarmos o que se conceituava como um "Estado Mínimo" [...] Ao mesmo tempo, as gestões dos governos das frentes populares começaram a implementar experiências baseadas em processos mais participativos, com um desenho mais social e que se opunha tanto a um modelo altamente burocratizado, quanto ao da redução das ações estatais em direção à estruturação de uma política de "Estado Mínimo" (CALABRE, (2015, p. 7).
\end{abstract}

Diante de tal contexto, a pergunta inquietante é: se estávamos diante de uma Constituição tão democratizadora para com a cultura e que a coloca como um direito de todos, por que no período posterior à sua vigência, ações como a do "Estado Mínimo" foram postas em vigor em detrimento do campo cultural?

A este respeito, Machado (2007) traça uma distinção entre política pública de cultura e política governamental de cultura. Afirma que a segunda 
mantém as características de baixa participação da sociedade e promoção dos governos, o que leva à execução de ações de curta duração (tempo da gestão governamental que a implanta). Por sua vez, uma política pública de cultura é o oposto. A prioridade é garantir a universalização dos direitos culturais por meio de ações de longo prazo e/ou serviços culturais permanentes, como resultado do envolvimento efetivo da sociedade.

Desta maneira, o que fica explícito é que uma política cultural efetivamente pública, possível em decorrência da Constituição, naquele momento histórico, só existe em tese. Apesar do direito à cultura estar previsto, na prática, observa-se a adoção de uma política governamental neoliberal e, portanto, voltada para a adaptação dos princípios do liberalismo clássico às exigências de um Estado regulador e, também, assistencialista, a que compete controlar, em parte, o funcionamento do mercado.

Neste caso, a lógica gira em torno do fundamento ideológico da cultura como um bom negócio. Tendo como principal suporte as leis de incentivo, as empresas só investem em marketing cultural se acenarem com a chance de deduzirem o valor investido do imposto devido ao Estado (BARBALHO, 2015). Isto ocasiona o patrocínio de bens culturais que atendam às demandas mercadológicas e não às demandas da sociedade, uma vez que é a iniciativa privada que detém o poder de decidir o que deve (ou não) ser financiado.

No período pós-promulgação da Constituição, registra-se, em 1990, a extinção do MinC, da Fundação Nacional de Artes, do SPHAN, do Instituto PróMemória, da Fundação Pró-Leitura, bem como de diversos outros órgãos culturais, sob o governo de Fernando Affonso Collor de Mello.

Outrossim, a criação da Lei n. 8.313, de 23 de dezembro de 1991 (BRASIL, 1991), que estimula investimentos da iniciativa privada em projetos culturais, com Sérgio Paulo Rouanet à frente do Ministério da Cultura e da Lei Sarney ou Lei n. 7.505 de julho de 1986 (BRASIL, 1986), proposta por Celso Furtado no período que foi ministro da cultura que estimula investimentos da iniciativa privada em projetos culturais, e configura-se numa adaptação da lei anterior de incentivo à cultura. A Lei Sarney, proposta por Celso Furtado, incorporava o modelo norte-americano de política cultural, baseada em leis de 
dedução de impostos, a qual permanece mesmo após tantos anos e governos, como um dos principais mecanismos federais de financiamento da cultura (BARBALHO, 2015).

Como avanço, cria-se o Sistema Nacional de Bibliotecas Públicas (SNBP), mediante o Decreto Presidencial n. 520, de 13 de maio de 1992 (BRASIL, 1992), como órgão subordinado diretamente à Fundação Biblioteca Nacional (FBN), vinculado ao MinC. No mesmo ano, a criação do Programa Nacional de Incentivo à Leitura (Proler) pretende promover o hábito de leitura, ainda que não haja, naquele momento, uma ligação:

[...] entre os "bens culturais" contidos na biblioteca pública com ações que levariam a um programa consistente de formação de leitores. Inexistia uma política de leitura vinculada ao acervo existente, apesar do livro trazer consigo a ideia de leitura [...] [Com relação ao Proler] detectam-se problemas em que os convênios com instituições públicas e privadas são necessários para que este Programa dê certo. Não se percebe uma responsabilidade do governo em implantar e consolidar um Programa de Leitura, sustentado por ele mesmo. O governo repassa para a sociedade a responsabilidade em manter e implantar programas de leitura no país (CALDAS; TÁLAMO, 2007, p. 4).

Outro avanço culminado com o Decreto n. 3.551, de 4 de agosto de 2000 (BRASIL, 2000), fruto de amplos debates, se dá graças ao reconhecimento institucional do patrimônio cultural imaterial brasileiro. De acordo com o Instituto do Patrimônio Histórico e Artístico Nacional (IPHAN), amparado na Carta Magna vigente, os bens culturais de natureza imaterial referem-se às práticas e aos domínios da vida social que se manifestam em “[...] saberes, ofícios e modos de fazer; celebrações; formas de expressão cênicas, plásticas, musicais ou lúdicas e nos lugares, tais como mercados, feiras e santuários que abrigam práticas culturais coletivas." (IPHAN, 2017).

Com a gestão de Gilberto Gil, entre 2003 e 2006, pode-se falar em real construção do MinC, cuja estrutura é reformulada. Inicia-se, ainda, um diálogo com a sociedade, por meio de consultas populares (CALABRE, 2015). Nessa gestão, o Programa Livro Aberto, ano 2004, é o responsável pela ampliação do número de bibliotecas públicas e modernização das já existentes.

Em 2005, ocorre a I Conferência Nacional de Cultura, com ampla participação de diversos setores da sociedade, cujos diálogos geram as diretrizes 
presentes no Plano Nacional de Cultura, aprovado por meio da Lei n. 12.343, de 2 de dezembro de 2010 (BRASIL, 2010b). Retomando-se o PNC, acresce-se que está ele regido pelos seguintes princípios:

\footnotetext{
I - liberdade de expressão, criação e fruição;

II - diversidade cultural;

III - respeito aos direitos humanos;

IV - direito de todos à arte e à cultura;

V - direito à informação, à comunicação e à crítica cultural;

VI - direito à memória e às tradições;

VII - responsabilidade socioambiental;

VIII - valorização da cultura como vetor do desenvolvimento sustentável;

IX - democratização das instâncias de formulação das políticas culturais;

$\mathrm{X}$ - responsabilidade dos agentes públicos pela implementação das políticas culturais;

XI - colaboração entre agentes públicos e privados para o desenvolvimento da economia da cultura;

XII - participação e controle social na formulação e acompanhamento das políticas culturais. (BRASIL, 2010b, p. 2).
}

O Programa Livro Aberto, por sua vez, como resultado de esforço coletivo, abrange um entendimento de cultura baseado em três dimensões. São elas: simbólica (como expressão); cidadã (como direito); e econômica (campo para desenvolvimento sustentável), contemplando diversos grupos da sociedade, linguagens artísticas, equipamentos e instituições culturais.

Em se tratando das bibliotecas, dentre as instituições culturais, elas se fazem presentes diretamente ou indiretamente no PNC em sete metas (BRASIL, 2011). De forma sucinta, retomam-se seus conteúdos. Por exemplo: meta 2 $100 \%$ das Unidades da Federação e 60\% dos municípios com dados atualizados no Sistema Nacional de Informações e Indicadores Culturais (SNIIC); meta 6 $50 \%$ dos povos e comunidades tradicionais e grupos de culturas populares que estiverem cadastrados no SNIIC atendidos por ações de promoção da diversidade cultural, incluindo-se a inserção ou a melhoria de bibliotecas em áreas quilombolas e indígenas.

Com vinculação direta ao PNLL, a meta 20 do PNC prescreve a média ideal de quatro livros lidos, por ano, por cada brasileiro, além dos muros das escolas, o que prevê a instalação de bibliotecas em todas as cidades, com equipamentos, acervo e funcionários suficientes para mantê-las em 
funcionamento. É a capacitação de pessoas que atuem na democratização do acesso ao livro e na formação de leitores com vistas a apoiar novos espaços de leitura, como salas de leitura, bibliotecas circulantes, bibliotecas comunitárias, acervos em hospitais e associações comunitárias.

A meta 29 refere-se à existência de acessibilidade e desenvolvimento de atividades de fruição cultural em $100 \%$ das bibliotecas públicas e dos demais equipamentos culturais públicos do país. Indo além, a meta 32 prevê que todos os municípios mantenham pelo menos uma biblioteca pública em funcionamento, enquanto a de número 34 pretende que, até 2020, 50\% das bibliotecas e museus estejam devidamente modernizados.

Por fim, a meta 41 estipula que $100 \%$ de bibliotecas públicas, ao lado de $70 \%$ de museus e arquivos, disponibilizem informações sobre seu acervo no SNIIC. Desdobrando-se em outras 11 estratégias e ações no PNC, a biblioteca é contemplada dentre as estratégias e ações previstas na Lei n. 12.343 (BRASIL, 2010b), ou seja, no PNC, a biblioteca se faz presente nos seguintes momentos/itens:

2.5.8 [...] criação de centros integrados da memória (museus, arquivos e bibliotecas); 2.5.9 Fomentar a instalação e a ampliação de acervos públicos [...] em bibliotecas; 3.1.12 Reabilitar [...] bibliotecas [...] criando programas estaduais e municipais de circulação de produtos, circuitos [...], eventos culturais; 3.1.15 Estabelecer critérios técnicos para a construção e reforma de [...] bibliotecas; 3.1.17 Implementar uma política nacional de digitalização e atualização tecnológica de [...] acervos culturais mantidos em [...] bibliotecas [...]; 3.1.18 Garantir a implantação e manutenção de bibliotecas em todos os municípios brasileiros como espaço fundamental de informação, de memória literária, da língua e do design gráfico, de formação e educação, de lazer e fruição cultural [...] 3.3 Organizar em rede a infraestrutura [...] bibliotecas [...] 3.5.9 cineclubes em [...] bibliotecas públicas [...] 3.6.5 Estimular o compartilhamento pelas redes digitais de conteúdos que possam ser utilizados livremente por [...] bibliotecas de acesso público $[. .$.$] ; 4.4.11 Capacitar [...] bibliotecários [...] para a atuação$ como agentes de difusão da leitura, contadores de histórias e mediadores de leitura em escolas, bibliotecas e museus, entre outros equipamentos culturais e espaços comunitários; 5.1.3 Potencializar os equipamentos e espaços culturais, bibliotecas [...] como canais de comunicação e diálogo com os cidadãos e consumidores culturais, ampliando sua participação direta na gestão destes equipamentos (BRASIL, 2010b, p. 20-33). 
Tudo isto comprova que bibliotecas e bibliotecários (vide item 4.4.1 da citação supra) estão integrados à efetivação do PNC, com o objetivo de inclusão no setor cultural brasileiro com o intuito de incentivo à leitura, acessibilidade à fruição cultural e garantia à informação.

Outra política nacional que também contempla a biblioteca através de ações efetivas vem do PNLL. Suas metas organizam-se em quatro eixos principais de atuação: (1) democratização do acesso - privilégio às bibliotecas de acesso público; (2) fomento à leitura e à formação de mediadores - valoração de fomentadores que ajudem a formar leitores; (3) valorização do livro e da comunicação - trabalhar o livro como valor social e cultural e como bem público a se preservar como direito de cidadania; (4) desenvolvimento da economia do livro, ou seja, não separar a leitura de sua base material. O livro, em suportes impressos ou digitais, constitui, sempre, a base de uma economia da cultura a ser apoiada e defendida.

Em outras palavras, no PNLL, as

[...] diretrizes para uma política pública voltada à leitura e ao livro no Brasil (e, em particular, à biblioteca e à formação de mediadores), apresentadas no Plano, levam em conta o papel de destaque que essas instâncias assumem no desenvolvimento social e da cidadania e nas transformações necessárias da sociedade para a construção de um projeto de nação com uma organização social mais justa. Elas têm por base a necessidade de formar uma sociedade leitora como condição essencial e decisiva para promover a inclusão social de milhões de brasileiros no que diz respeito a bens, serviços e cultura, garantindo-lhes uma vida digna e a estruturação de um país economicamente viável (BRASIL, 2010a, p. 1).

Com o PNC e o PNLL, constituem-se então políticas nacionais de significativa abrangência, que, pela primeira vez na história das políticas públicas de cultura no país, priorizam ações voltadas à biblioteca de forma tão desafiadora e complexa. Desta maneira, a partir de análise das três bibliotecas do Cariri cearense, antes mencionadas, investigam-se essas políticas de maneira a descobrir se conseguem ser elas efetivadas graças às medidas realizadas no âmbito das bibliotecas.

\section{Políticas culturais e bibliotecas: experiências no Cariri cearense}


O Cariri cearense é um território que abrange 27 municípios no extremo sul do Estado do Ceará, de onde se destaca, como região metropolitana, o chamado aglomerado urbano CRAJUBAR, oriundo das três cidades mais importantes que o constitui: Crato, Juazeiro do Norte e Barbalha.

No Cariri, a ocupação mais intensiva das atividades urbanas nos territórios dos municípios de Crato, Juazeiro do Norte e Barbalha, associada à histórica relação de interdependência e complementaridade entre eles, aliada à proximidade física entre os núcleos urbanos destes municípios, promoveu a formação do aglomerado urbano que se convencionou chamar de Crajubar (QUEIROZ, 2014, p. 96).

Por suas condições climáticas mais favoráveis, aliado a recursos naturais, hidrográficos e por condições sócio-históricas, que proporcionam o desenvolvimento da região, esse território é conhecido, hoje, por ser um polo industrial, turístico, educacional e cultural. Com relação a este último item, sua expressividade manifesta-se de maneiras distintas. Além de fortemente presente no cotidiano, entre artistas, gestores culturais e pesquisadores, é comum referirse a esse lugar como verdadeiro caldeirão cultural.

Em Juazeiro do Norte, diversas manifestações de tradição são contempladas pelo Projeto do Estado, "Tesouros vivos da cultura", na figura de seus mestres ou grupos. Instituições culturais na cidade, como Centro Cultural Banco do Nordeste (CCBNB) e Serviço Social do Comércio (SESC), estão diretamente envolvidas na gestão e na promoção da cultura local, além de outras entidades, como Centro Cultural Mestre Noza e Lira Nordestina, de grande relevância para o cenário da cultura. A cidade é também marcada por romarias, em decorrência do milagre da hóstia, cujos protagonistas são a Beata Maria de Araújo e o Padre Cícero.

No Crato, a cultura manifesta-se em grupos de tradição, mantidos por figuras importantes no local, como os Irmãos Aniceto (banda Cabaçal) e Mestre Aldenir (reisado). Em outras linguagens, citam-se o poeta e músico Abidoral Jamacaru e o Grupo Ninho de Teatro, reconhecido em território nacional.

Em Barbalha, a celebração para o padroeiro da cidade, que congrega festividades religiosas, culturais e artísticas durante 13 dias, levou a Festa de 
Santo Antônio de Barbalha, ano 2015, ao título de patrimônio cultural imaterial brasileiro concedido pelo IPHAN.

A explanação, ainda que sucinta, acerca dos bens, grupos e manifestações culturais do Cariri cearense, especificamente do Crato, Juazeiro do Norte e Barbalha, tem o intuito de explicitar a relevância da cultura para a população, e, portanto, para suas bibliotecas, situando o leitor em meio à pluralidade e à diversidade cultural existentes. Assim, diante de cenário cultural tão complexo, apresenta-se o diagnóstico de como estão sendo aplicadas as políticas nacionais de cultura, no âmbito das bibliotecas do Cariri cearense.

\subsection{Biblioteca Inspiração Nordestina}

A Biblioteca Inspiração Nordestina faz parte dos serviços oferecidos pelo CCBNB. Atua como centro de informação, cultura e pesquisa, através de um acervo de livros, CD, DVD, mapas, jornais, revistas, dicionários, enciclopédias gerais e específicas, histórias em quadrinhos (adulto e infantil), cordéis, etc.

Inaugurada em abril de 2006, em Juazeiro do Norte, a Biblioteca conta com mais de 10 anos de funcionamento, um acervo com mais de 16 mil obras, salas de estudo individual e em grupo, além de cabines de vídeo. Daí, o local ser utilizado por um público bastante diversificado, como crianças em situação de vulnerabilidade socioeconômica que usufruem do espaço em busca de lazer via leitura de livros e exibição de filmes; adolescentes; universitários; concurseiros que vão estudar ou alugar (prática comum nas bibliotecas brasileiras) obras de seu interesse; pais que levam os filhos durante finais de semana em busca de recreação, etc.

Ao observar apenas o perfil de seu público, poder-se-ia pensar que o espaço abriga uma biblioteca pública. $\mathrm{Na}$ verdade, trata-se de biblioteca especializada em arte, cultura e literatura, que atende diariamente a um público bem mais vasto do que seu escopo de atuação. Porém, contrariando o previsto pelo PNC, quando descreve a importância de capacitar profissionais para atuar como agentes de difusão da leitura (BRASIL, 2010b), atualmente, a Biblioteca encontra-se sem bibliotecário-gestor. Após o corte financeiro desde o final de 2014, colaboradores terceirizados foram demitidos, incluindo os 13 
bibliotecários responsáveis pelas diversas unidades da instituição. Em termos atuais, o quadro de funcionários restringe-se a três auxiliares de biblioteca (duas com graduação em Biblioteconomia e uma, no último período do curso), além de uma estudante do ensino médio, que participa do Projeto "Jovem Aprendiz".

Mensalmente, a Biblioteca realiza atividades como o Clube do Leitor, Conversas filosóficas e contações de histórias. O Clube do Leitor é um programa mensal de difusão e apreciação literária, visando estimular o leitor através da discussão de obras e autores. Os encontros costumam atrair um público de alunos do ensino médio e universitários por conta das variadas temáticas, que passeiam entre autores nacionais e estrangeiros.

O programa Conversas filosóficas objetiva refletir sobre um tema preestabelecido, em geral, tópicos em evidência no cotidiano, por meio de um convidado que media as discussões à luz de obras filosóficas. As contações de histórias, por seu turno, compõem as atividades do programa infantil, o qual envolve vários espaços no Centro Cultural com jogos educativos na biblioteca virtual, peças de teatro, oficina e recreação. Acontecem todos os sábados na Biblioteca, levando as crianças a terem contato com diferentes histórias e personagens, através dos vários elementos utilizados na contação.

Sobre estas ações, ao responder ao questionário, a auxiliar de biblioteca que atua há mais tempo na instituição e que, apesar de bibliotecária por formação, não exerce a função, considera que a programação descrita contribui diretamente para o incentivo à leitura, sobretudo, o Clube do Leitor e as contações de histórias, voltadas para crianças/adolescentes entre dois e 14 anos. Em sua opinião, as iniciativas representam oportunidade de acesso à leitura, literatura, cultura e arte, embora, reconheça a falta de profissionais para exercício da função de mediador bibliotecário, uma vez que o cargo permanece desocupado. Este fato compromete o desempenho da Biblioteca como instituição social e contraria tanto o item 4.4.11 do PNC (transcrito antes, literalmente) quanto à meta número dois do PNLL, que enfatiza o fomento à leitura via mediadores devidamente habilitados.

A depoente também destaca o problema da falta de autonomia. Por exemplo, ao propor novos programas, estes precisam passar por um Conselho 
Consultivo da célula de cultura do Banco do Nordeste, em Fortaleza, Ceará, que analisa a proposta e pode tanto aprovar quanto reprovar ou modificar. A questão em torno disso é que, quase nunca, as propostas chegam até a célula. E quando chegam, os membros do Conselho, como desconhecem a realidade da região, encontram dificuldade em avaliar as propostas de maneira a atender às demandas da região.

De qualquer forma, como decorrência da observação direta e do contato com a equipe da Biblioteca e o público em geral, acredita-se que as iniciativas em vigor, apesar de anteriores à instituição dos dois planos, evidenciam seu caráter vanguardista e contribuem diretamente para sua efetivação, a exemplo da meta 20 do PNC e das ações do eixo I (democratização do acesso) do PNLL.

\subsection{Biblioteca do Centro de Artes e Esportes}

As bibliotecas do Centro de Artes e Esportes (CEU) são iniciativa recente do MinC, que integra um programa com várias ações, tendo em vista a promoção da cidadania em espaços de alta vulnerabilidade social. Dentre as medidas, estão ações culturais, práticas esportivas e de lazer, formação e qualificação para o mercado de trabalho, serviços socioassistenciais, políticas de prevenção à violência e de inclusão digital.

No programa em pauta, a Biblioteca trabalha de modo a colaborar para a ampliação do acesso à informação, à leitura e à cultura, por meio de seu acervo, suas áreas e seus serviços que tendem a atender diferentes interesses de leitura e de informação da comunidade.

Sua implantação resulta da adoção das diretrizes criadas pelo SNBP. Além dos procedimentos de acesso, as bibliotecas também recebem atividades, como saraus, oficinas literárias e debates com a comunidade, entre outras alternativas que visem despertar o interesse pela leitura e produção de textos.

Na prática, a Biblioteca do CEU, localizada em Barbalha e inaugurada em agosto de 2013, está aberta a toda comunidade, qualquer que seja o perfil de seus integrantes, porém, não oferece serviço de empréstimo, limitando-se à consulta local. A bibliotecária é responsável pelo serviço de referência e processamento técnico da coleção, mas a gestão está sob responsabilidade do 
titular da secretaria de cultura. Este fato contraria o previsto por teóricos revistados na seção anterior, à semelhança de Caldas e Tálamo (2007) e Leitão (2010), e, também, pelos dois planos governamentais (PNC e PNLL), que enaltecem a permanência de experts em bibliotecas e instituições congêneres.

Quer dizer, o fato de a gestão da Biblioteca (decisões sobre recursos financeiros, de pessoal, desenvolvimento de coleções) não estar sob a incumbência de profissional especializado revela muito acerca das chances de atuação e de reconhecimento do bibliotecário em âmbito institucional no município de Barbalha. A formação profissional, que garante competências para o desenvolvimento de atividades no âmbito técnico, social e de gestão, é, assim, desconhecida ou desconsiderada pelos gestores municipais.

Segundo a bibliotecária contatada via questionário, a Biblioteca mantém parceria com o Centro de Referência da Assistência Social (CRAS), que fomenta o incentivo à leitura por meio de atividades realizadas com crianças na faixa etária entre cinco e 14 anos, oriundas de situações de violência e de vulnerabilidade socioeconômica.

Dentre as ações desenvolvidas, a depoente cita os Projetos "Amigos da Leitura" e "Barbalha Cresce Brincando" realizada entre a Biblioteca do CEU e a Biblioteca Pública da cidade. Entre as atividades, estão: contações de histórias e leitura de livros em grupo. Há, também, criação de história. Neste caso, trata-se de metodologia adotada por assistentes sociais para avaliação com crianças acerca de traumas e violências vividas: lê-se uma historinha e pede que elas desenhem sobre o relato ouvido. Muitas vezes, os desenhos vão além da história. Relacionam-se com o cotidiano - de violência - da própria criança. Por fim, no período de férias escolares, é realizado o Projeto "Férias e diversão na Biblioteca do CEU', que trabalha com leitura e jogos em abordagem psicopedagógica.

Entretanto, apesar do grande público, diariamente presente na Biblioteca, lendo e/ou resolvendo atividades escolares, e da forte aproximação com a comunidade situada no entorno, a bibliotecária entrevistada destaca a falta de sensibilidade dos gestores públicos para com a Biblioteca e seus profissionais. 
O não repasse de verbas e de recursos comprometem o desenvolvimento pleno das atividades planejadas. No que tange ao bibliotecário, a lacuna em torno do reconhecimento de sua atuação e a falta de autonomia para executar ações e projetos também fragilizam seu desempenho. Percebe-se que nas bibliotecas do CEU, apenas a meta 20 do PNC é efetivada, devido a significativos esforços da bibliotecária, que parece atuar sem incentivo, recurso ou valorização profissional.

\subsection{Biblioteca Pública do Crato}

A Biblioteca Pública está inclusa nos fatores qualitativos da UNESCO, para que se tenha uma sociedade leitora, com acesso garantido ao livro e a um número suficiente de bibliotecas presentes em todos os municípios do país (BRASIL, 2010a). Segundo o PNC, a biblioteca pública está em 99\% dos municípios brasileiros, embora quantidade não signifique qualidade, dado que apesar de estar presente em grande parte dos municípios é também um dos menos presentes no cotidiano da população, como evidenciado na pesquisa "Retratos da leitura" realizada pelo Instituto Pró-Livro, quarta edição, ano 2016. Diante da pergunta sobre o que lhe faria frequentar uma biblioteca, a reposta obtida mais recorrente (30\%) dentre os sujeitos do estudo refere-se a de que nada estimula sua ida às bibliotecas (INSTITUTO PRÓ-LIVRO, 2016).

Ainda em consonância com a fonte ora referida, recursos humanos insuficientes (média de quatro); falta de infraestrutura de qualidade (49\% dos próprios dirigentes, levando em conta quesitos, como iluminação, ventilação, mobiliário e equipamentos, disseram ser inadequados na biblioteca onde trabalham), profissionais capacitados (dos $57 \%$ dos dirigentes com ensino superior, apenas $11 \%$ são graduados em Biblioteconomia) e acervo defasado constituem alguns dos motivos para a "inexistência" da biblioteca pública no dia a dia dos brasileiros, em que pesem sua importância social, como Targino (2006) descreve em detalhes.

Porém, em Crato, a Biblioteca Pública vivencia uma realidade um tanto diferente em confronto com parâmetros nacionais. Está vinculada à Coordenadoria de Políticas Públicas para Livro e Leitura (COPLIL) da 
Secretaria de Cultura do Crato, contando com dois bibliotecários que se dividem entre a coordenação da COPLIL e a gestão de bibliotecas e ações literárias.

Ao participar da pesquisa, a Coordenadora de Políticas Públicas para Livro e Leitura, que também está à frente da gerência de editoração e pesquisa e da produção cultural, explica que são desenvolvidas ações, como contação de história; editoração de publicações em livreto ou cordel; e incentivo à leitura em parceria com escolas próximas à Biblioteca. Segundo seu depoimento, as ações convergem tanto para cumprir as metas nacionais quanto para atender aos parâmetros municipais, posto que Crato é uma das cidades com Plano Municipal de Cultura (PMC) em vigor, com metas e projetos para as bibliotecas. Entre eles: programa de revitalização e modernização da infraestrutura física da Biblioteca Pública Municipal do Crato e da Biblioteca Pública Luiz Cruz; Programa bibliotecas, comunidades e sociedade civil; Programa de fomento e difusão da cultura literária.

Recentemente, recebeu 500 livros da Secretaria de Cultura do Ceará para atualização do acervo da biblioteca comunitária e sua equipe está à frente do "Projeto RECODE" em Bibliotecas do Instituto Bill e Merlinda Gates em parceria com a Diretoria de Livro, Leitura, Literatura e Bibliotecas (DLLLB) do MinC. Daí, da fala da entrevistada, verifica-se flagrante otimismo diante da ampliação de ações dentro e fora da Biblioteca, até porque, como se trata de uma biblioteca pública, a abrangência dos usuários ajuda a alcançar diferentes setores da sociedade. O negativo é a falta de incentivo financeiro da Prefeitura para a realização de algumas atividades sugeridas pelos bibliotecários.

Apesar disso, constata-se que, possivelmente, pelo fato de já ter o PMC instituído, o que garante maior fortalecimento em sua performance, a Biblioteca cumpre as citadas metas 20,32, 41 do PNC e as diretrizes do Eixo I (bibliotecários como promotores da leitura e atualização de acervos por meio de programas permanentes de atualização) do PNLL.

\section{Considerações finais}

Uma das características básicas que constitui uma política cultural vem do fato de apresentar continuidade e de manter sua base de articulação entre Estado e 
sociedade, a fim de instituir de maneira participativa na área da cultura, ações que colaborem de maneira a sanar as demandas dos diversos segmentos sociais.

No que se refere às políticas nacionais em vigor, PNLL e PNC, é possível perceber que estas possibilitam integrar de maneira abrangente, sistematizada e continuada, iniciativas no setor cultural brasileiro, e que conferem pela primeira vez na história das políticas culturais do Brasil, papel de destaque para as bibliotecas.

Para bibliotecários ou pesquisadores do campo da Biblioteconomia e Ciência da Informação, é clara e explícita a importância das bibliotecas, suas funções e possibilidades de atuação, que vão desde a esfera social (por ser espaço de compartilhamento, encontro e trocas); passando pela educativa (produção do conhecimento); cultural (por congregar por meio de seu acervo e ações diferentes expressões e linguagens da cultura); e de memória (por consistir espaço de registro e salvaguarda da produção do conhecimento humano).

Nesse sentido, acredita-se que o atual reconhecimento institucional da importância das bibliotecas por via das políticas culturais, configura-se como avanço e mecanismo importante a ser adotado pelos bibliotecários brasileiros.

No caso específico das três bibliotecas situadas no Cariri cearense, infere-se que, não obstante as muitas dificuldades e barreiras enfrentadas, suas ações e atividades contribuem diretamente para a efetivação das metas propostas nos planos, sem que fique claro, porém, como se dá a intervenção do MinC no que concerne ao repasse de recursos. Aliás, todas elas apresentam quase a mesma problemática: falta de investimentos para melhor desenvolvimento das ações; ausência de autonomia na proposição e execução de novas ações; não reconhecimento por parte do poder público do trabalho desenvolvido.

Reitera-se a necessidade de trazer os debates sobre as políticas culturais públicas na esfera da Biblioteconomia. Há, inclusive, quem questione se, falar em política de informação já não significa falar de política cultural, visto que falar em política cultural é tratar de fenômenos informacionais que evocam questões de uso, apropriação e circulação de informações, assim como em produção e organização do conhecimento. 
Neste sentido, espera-se ter corroborado para fomentar o debate e produzir novas reflexões acerca das ações que o bibliotecário pode desenvolver, tendo as políticas culturais como instrumentos efetivos. Isto porque, o recorte geográfico de um estudo alusivo ao Cariri cearense, de forma mais ou menos próxima, reflete a realidade de diferentes localidades do Brasil, em seus pontos de sucesso e/ou de estrangulamento.

\section{Referências}

ABUD, K. M. Formação da alma e do caráter nacional: ensino de história na Era Vargas. Revista Brasileira de História, São Paulo, v. 18, n. 36, p. 103-114, 1998.

BARBALHO, A. Política cultural no Brasil: perspectiva histórica. In: CURSO de aperfeiçoamento para gestores públicos de cultura. [S.l.]: Universidade Federal do Cariri: MinC, 2015. Material didático.

BRASIL. Ministério da Cultura. Metas do plano nacional de cultura. 2011.

BRASIL. Plano nacional do livro e da leitura. Brasília: MinC, 2010a.

BRASIL. Decreto n. 3.551, de 4 de maio de 2000. Institui o Registro de Bens Culturais de Natureza Imaterial que constituem patrimônio cultural brasileiro, cria o Programa Nacional do Patrimônio Imaterial e dá outras providências. Diário Oficial [da] República Federativa do Brasil, Poder Legislativo, Brasília, DF, 7 de agosto de 2000. Seção 1, p. 2.

BRASIL. Decreto n. 520, de 13 de maio de 1992. Institui o Sistema Nacional de Bibliotecas Públicas e dá outras providências. Diário Oficial [da] República Federativa do Brasil, Poder Legislativo, Brasília, DF, 14 de maio de 1992. Seção 1, p. 6030.

BRASIL. Lei n. 12.343, de 2 de dezembro de 2010. Institui o Plano Nacional de Cultura - PNC, cria o Sistema Nacional de Informações e Indicadores Culturais SNIIC e dá outras providências. Diário Oficial [da] República Federativa do Brasil, Poder Legislativo, Brasília, DF, 3 dez. 2010b. Seção 1, p. 1-13.

BRASIL. Lei n. 7.505, de 2 de julho de 1986. Dispõe sobre benefícios fiscais na área do imposto de renda concedidos a operações de caráter cultural ou artístico. Diário Oficial [da] República Federativa do Brasil, Poder Legislativo, Brasília, 3 de julho de 1986. Seção 1, p. 9763.

BRASIL. Lei n. 8.313, de 23 de dezembro de 1991. Restabelece princípios da Lei n ${ }^{\circ} 7.505$, de 2 de julho de 1986, institui o Programa Nacional de Apoio à Cultura (Pronac) e dá outras providências. Diário Oficial [da] República 
Federativa do Brasil, Poder Legislativo, Brasília, DF, 24 de dezembro de 1991. Seção 1, p. 30261.

CALABRE, L. Introdução às políticas públicas. In: CURSO de aperfeiçoamento para gestores públicos de cultura. [S.1.]: Universidade Federal do Cariri: MinC, 2015. Material didático.

CALABRE, L. Políticas culturais no Brasil: balanços e perspectivas. In: ENCONTRO DE ESTUDOS MULTIDISCIPLINARES EM CULTURA, 3., 2007, Salvador. Anais eletrônicos... Salvador, 2007.

CALDAS, E. F.; TÁLAMO, M. de F. G. M. Biblioteca pública no Brasil: políticas de incentivo à leitura. In: CONGRESSO DE LEITURA, 16., 2007, São Paulo. Anais... São Paulo: ABL, 2007.

HOCHMAN, G.; ARRETCHE, M. T. S.; MARQUES, E. C. (Org.). Políticas públicas no Brasil. Rio de Janeiro: FIOCRUZ, 2007.

INSTITUTO DO PATRIMÔNIO HISTÓRICO E ARTÍSTICO NACIONAL. O que é patrimônio imaterial? 2017.

INSTITUTO PRÓ-LIVRO. Retratos da leitura. 4. ed. Rio de Janeiro, 2016.

LEITÃO, B. J. M. A relação entre as bibliotecas públicas, bibliotecários e a censura na Era Vargas e regime militar: uma reflexão. 2010. Tese (Doutorado em Ciência da Comunicação) - Universidade de São Paulo, São Paulo, 2010.

MACHADO, B. N. da M. Direitos culturais e políticas para a cultura: Curso de Gestão e Desenvolvimento Cultural Pensar e Agir com Cultura, Cultura e Desenvolvimento Local. Belo Horizonte: [s.n.], 2007.

MEDEIROS, A. E. de A. Imaterialidade criadora. In: TEIXEIRA, J. G. L. C.; GARCIA, M. V. C.; GUSMÃO, R. (Org.). Patrimônio imaterial, performance cultural e (re) tradicionalização. Brasília: UnB, 2004.

MEDEIROS, V. da S.; ALMEIDA, N. R. de; VAS, B. B. Do INL à digitalização de acervos: breve panorama da biblioteca pública no Brasil. Entreletras, Araguaína, v. 5, n. 1, p. 42-61, 2014.

MENDONÇA, S. R. de. As bases do desenvolvimento capitalista dependente: da industrialização restringida à internacionalização. In: LINHARES, M. Y. (Org.). História geral do Brasil. Rio de Janeiro: Elsevier, 1990.

ORTIZ, R. Cultura brasileira e identidade nacional. São Paulo: Brasiliense, 2006. 
ORTIZ, R. Imagens do Brasil. Sociedade e Estado, Brasília, v. 28, p. 609-633, 2013.

QUEIROZ, I. S. Região metropolitana do Cariri cearense, a metrópole fora do eixo. Mercator, Fortaleza, v. 13, p. 93-104, 2014.

RUBIM, A. Políticas culturais no Brasil: tristes tradições, enormes desafios. In: BARBAlHO, A.; RUBIM, A. (Org.). Políticas culturais no Brasil. Salvador: UFBA, 2007. p. 11-36.

TARGINO, M. das G. Olhares e fragmentos: cotidiano da Biblioteconomia e Ciência da Informação. Teresina: Edufpi, 2006.

\title{
Cultural policies and libraries of Cariri cearense
}

\begin{abstract}
This paper discusses the culture and its instrumentalization in the form of public policies within the Brazilian libraries. It aims to know to what extent the libraries are inserted in the national policies of culture - National Plan of Culture and the National Plan of the Book and Reading - and how the goals of these plans have been applied. It is established a review of the programs and projects developed in three libraries of Cariri Cearense - Library Inspiração Nordestina in Juazeiro do Norte, Library of the Center of Arts and Sports in Barbalha and the Public Library of the city of Crato - due to the variety and cultural diversity existing in that location. It carries out the study through a bibliographical review and the application of questionnaires for librarians and assistants of the libraries analyzed. It concludes that although there are many difficulties and barriers to the full functioning of libraries, actions and activities contribute to the achievement of the goals proposed in the plans, as well as the relevance of this discussion within Librarianship, since speaking in cultural politics is refer to informational phenomena, which evoke questions of use, appropriation and circulation of information, as well as in production and organization of knowledge.
\end{abstract}

Keywords: Public policies of culture. Libraries. Cultural actions. Cariri Cearense.

Recebido: 02/02/2017

Aceito: 04/06/2017 